\title{
Study of the corrosion behaviors of 304 austenite stainless steel specimens exposed to static liquid lithium at $600 \mathrm{~K}$
}

\author{
Xiancai Meng ${ }^{\mathrm{a}, \mathrm{b}}$, Guizhong Zuo ${ }^{\mathrm{b}}$, Jun Ren ${ }^{\mathrm{b}}$, Wei Xu ${ }^{\mathrm{b}}$, Zhen Sun ${ }^{\mathrm{b}}$, Ming Huang ${ }^{\mathrm{b}}$, \\ Wangyu $\mathrm{Hu}^{\mathrm{a}}$, Jiansheng $\mathrm{Hu}^{\mathrm{b},{ }^{*}}$, Huiqiu Deng ${ }^{\mathrm{a},{ }^{*}}$ \\ ${ }^{\mathrm{a} D e p a r t m e n t ~ o f ~ A p p l i e d ~ P h y s i c s, ~ S c h o o l ~ o f ~ P h y s i c s ~ a n d ~ E l e c t r o n i c s, ~ H u n a n ~}$ \\ University, Changsha 410082, China. \\ ${ }^{\mathrm{b}}$ Institute of Plasma Physics, Chinese Academy of Sciences, Hefei, 230031, \\ China. \\ *Corresponding authors. E-mails: hujs@ipp.ac.cn (J. S. Hu), \\ hqdeng@hnu.edu.cn (H. Q. Deng)
}

\begin{abstract}
Investigation of corrosion behavior of stainless steel served as one kind of structure materials exposed to liquid lithium ( $\mathrm{Li}$ ) is one of the keys to apply liquid $\mathrm{Li}$ as potential plasma facing materials (PFM) or blanket coolant in the fusion device. Corrosion experiments of 304 austenite stainless steel (304SS) were carried out in static liquid $\mathrm{Li}$ at $600 \mathrm{~K}$ and up to1584 hours at high vacuum with pressure less than $4 \times 10^{-4} \mathrm{~Pa}$. After exposure to liquid $\mathrm{Li}$, it was found that the weight of $304 \mathrm{SS}$ slightly decreased with weight loss rate of $5.7 \times 10^{-4} \mathrm{~g} / \mathrm{m}^{2} / \mathrm{h}$ and surface hardness increased by about 50HV. Lots of spinel-like grains and holes were observed on the surface of specimens measured by SEM. By further EDS, XRD and metallographic analyzing, it was confirmed that the main compositions of spinel-like grains were $\mathrm{M}_{23} \mathrm{C}_{6}$ carbides, and 304SS produced a non-uniform corrosion behavior by preferential grain boundary attack, possibly due to the easy formation of $\mathrm{M}_{23} \mathrm{C}_{6}$ carbides and/or formation of $\mathrm{Li}$
\end{abstract}


compound at grain boundaries.

\section{Introduction}

As a candidate material of plasma facing components (PFCs) for fusion devices, liquid $\mathrm{Li}$ has been got more and more attentions in recent decades. Li as an active metal with a low atomic number and is used as a trapper of residual gas for that it can react easily with $\mathrm{H}_{2} \mathrm{O}, \mathrm{O}_{2}, \mathrm{H}_{2}, \mathrm{CO}_{2}$ and $\mathrm{N}_{2}$ in fusion device, which can reduce effectively $\mathrm{H}$ isotopes recycling and decrease impurities content in the plasma [1-6]. Moreover, the flowing liquid $\mathrm{Li}$ wall in fusion device can continuously remove high particle and heat fluxes from plasma bombardment and self-heal the damaged wall materials $[7,8]$. By using liquid Li limiters (LLLs) in fusion device, the dramatically improvements of plasma performance have been obtained. For example, in FTU, T-11M and CDX-U devices, plasma discharges with lower impurity control and higher confinement were achieved by using LLL [9-14]. Some promising results were also achieved in HT-7 and EAST by using a LLL [7, 15-22]. It was found that the H recycling was reduced by $20-30 \%$, the particle confinement time increased by a factor of 2 , the impurity emission intensity was decreased by about $10-20 \%$ and the energy confinement time was increased by $20 \%$.

Liquid $\mathrm{Li}$ is also considered as a candidate material of blanket coolants and tritium breeders for fusion reactors. In these systems with liquid Li, most of structure materials of Li tanks and feeding pipes are stainless steel. The low activation ferritic steels and 321SS were used as the structure materials of liquid Li loops in IFMIF and IPPE. 316LSS and 304SS were used as the structure materials of liquid Li loops in JAEA and Osaka University [23-24]. Therefore, the wide application of liquid Li in fusion reactors requires a critical assessment of the compatibility of liquid Li with 
stainless steel structural materials. Some corrosion experiments of steel materials in liquid Li have been performed for different purposes. The compatibility of JLF-1 (a reduce activation ferrite/martensitic steel) and liquid $\mathrm{Li}$ were studied in static and flowing liquid $\mathrm{Li}$ [25-30]. The selective dissolution of $\mathrm{W}, \mathrm{Cr}$ and $\mathrm{C}$ was found for the JLF-1 in static liquid Li; then the phase transformation from martensite to ferrite was observed at $973 \mathrm{~K}$ due to $\mathrm{C}$ depletion. The weight loss of JLF-1 in static liquid Li at $873 \mathrm{~K}$ was larger than that at $773 \mathrm{~K}$. The weight loss of JLF-1 in flowing Li was one order of magnitude larger than that in static one. To investigate the mass transferring of elements in liquid $\mathrm{Li}$, Tortorelli [31] exposed the Fe-12Cr-1MoVW steel to thermally convective Li for 696 hours and found that Cr tended to be transported to the intermediated temperature part of the loop, but Ni tended to be transported to the coldest part of the loop. It was also found that some impurities, such as $\mathrm{N}$, have high solubility in $\mathrm{Li}$, which can enhance drastically the corrosion aggressiveness of $\mathrm{Li}$ [32-35].

As mentioned above, the corrosion behaviors of structural materials in liquid $\mathrm{Li}$ depend seriously on the experiment conditions. Several LLLs on HT-7 [16-20] and EAST [20-22] have been performed since 2009. Two kinds of static liquid lithium limiters with free surface and capillary-pore system (CPS) configuration were successively utilized in HT-7 in 2009 and 2011 with pressure less than $4 \times 10^{-5} \mathrm{~Pa}$. The structural materials used for the limiters base, pipes and Li tanks were 304SS or 316LSS, and the temperature of liquid Li was 500 700 K. To further guide the design and application of the components with liquid Li in EAST device, it is very necessary to study the corrosion behaviors and mechanisms of the stainless steel exposed to liquid $\mathrm{Li}$ at operation condition. Furthermore, it is demonstrated from the experimental results of wettability that the critical wetting temperature of liquid $\mathrm{Li}$ on 
SS was about $600 \mathrm{~K}$ [36]. In the present paper, the corrosion behavior of $304 \mathrm{SS}$ in static liquid $\mathrm{Li}$ at $600 \mathrm{~K}$ was investigated in detail.

\section{Experimental setup}

All the corrosion experiments were conducted in a static liquid Li testing device where it can be heated to more than $600 \mathrm{~K}$ and pumped to high vacuum condition (< $4 \times 10^{-4} \mathrm{~Pa}$ ) for suppressing $\mathrm{Li}$ interact with impurities. Fig. 1 shows the schematic diagram of static liquid Li testing device. The primary react vessel is a vacuum cylinder one with an inner diameter of $250 \mathrm{~mm}$ and a height of $330 \mathrm{~mm}$. A sampling system consists of a guide rod and a bellow with the diameter of $35 \mathrm{~mm}$ and the length of $320 \mathrm{~mm}$. By the bellow driving, it can push or pull the sample into or out of liquid Li. The vacuum system includes a turbo-molecular pump to get a high vacuum, a PCG vacuum gauge to monitor the vacuum, a leak detector to monitor the leak rate of vessel real-time. To protect the device safety, the function of safety interlock and protection was designed. If the react vessel's pressure is higher than $10 \mathrm{~Pa}$, the VED electromagnetic valve (Fig.1 (8)) will open and electromagnetic valve (Fig.1 (9)) will close, at the same time argon will fill to device upto $1 \mathrm{~atm}$. In addition, A DC power, three heater strips and two thermocouples constitute the heating and temperature measurement system. The viewing system consists of a Network Camera to monitor the whole condition of the experiment, an $\varnothing 100$ observation window on the top of vessel to observe the condition of liquid $\mathrm{Li}$ and specimens. The test vessel and fixture for loading the specimens are also made of 304SS to avoid addition mass transfer.

The specimens, with composition (wt \% analyzed by chemical method): $17.07 \mathrm{Cr}$, 2.4Mo, $1.00 \mathrm{Mn}, 10.31 \mathrm{Ni}, 0.026 \mathrm{C}, 0.34 \mathrm{Si}, 0.24 \mathrm{Cu}, 0.21 \mathrm{Co}, 0.045 \mathrm{Al}, 0.064 \mathrm{~S}$, and $\mathrm{Fe}$ as balance, is coupon-type with a size of $10 \mathrm{~mm}(\mathrm{~W}) \times 15 \mathrm{~mm}(\mathrm{~L}) \times 1 \mathrm{~mm}(\mathrm{~T})$. The 
surfaces of the specimens were mechanically polished before the experiment. Metal Li was supplied in ingots and the initial impurity contents were also listed in Table 1. Before test, six specimens were hung on the hooks in 20 millimeter off the bottom of test vessel, as show in Fig. 1. Then turned on the turbo-molecular pump to get a high vacuum in order to suppress the influence of impurities, then heated the test vessel to $380^{\circ} \mathrm{C}$ and kept about 12 hours. After finishing leak detection and vessel gas release, about $900 \mathrm{~g} \mathrm{Li}$ (The depth of liquid Li was about $35 \mathrm{~mm}$ when Li melted, all specimens were immersed) was placed into test vessel with Ar protection, and then the corrosion test started. The test vessel was heated up to $330^{\circ} \mathrm{C}$ (about $600 \mathrm{~K}$ ). The vacuum was less than $4.0 \times 10^{-4} \mathrm{~Pa}$ and the measured vessel leak rate was less than $1 \times 10^{-10} \mathrm{Pam}^{3} / \mathrm{s}$.

The corrosion experiments were conducted $600 \mathrm{~K}$ from $0 \mathrm{~h}$ to 1584 hours. After exposure, every 264 hours we turned off the heater to cool the device to ambient temperature. The specimens were removed from test vessel in Ar atmosphere. And then they were successively cleaned by flowing water and high purity alcohol to remove the remnant $\mathrm{Li}$ and get clear specimens. It can minimized the effect of a part of hydrogen be absorbed in the specimens and no degradation effects on the mechanical properties of specimens [30].

The corrosion rate was evaluated by means of weight measurement using electro-balance with an accuracy of $0.01 \mathrm{mg}$ before and after exposing to the liquid $\mathrm{Li}$. A Sirion200 scanning electron microscope (SEM) equipped with an energy dispersive spectrometer (EDS) and $\mathrm{X}$-ray diffraction analysis ( $\mathrm{XRD}, \mathrm{Cu} \mathrm{K} \alpha$ radiation) were used to characterize the microstructural and compositional changes of the corroded surface. The Vickers hardness was measured as a function of time under a load of 500gf with a loading time of 15 seconds. For each specimen, it would measure 5 points and then calculate the average value of 5 measurements to evaluate the hardness change. The 
metallurgical analysis was performed with the aid of an optical microscope, the specimens were ground using silicon carbide papers with a grids order of 800, 1200 and 2000 and mechanically polished by alumina powder with a diameter of $0.3 \mu \mathrm{m}$ and $0.05 \mu \mathrm{m}$ and then chemical etched in aqua regia about $3 \sim 5$ seconds.

\section{Results and discussion}

\subsection{Weight loss of the 304SS specimens}

The corrosion behaviors were evaluated by measuring the weight loss of the 304SS specimens exposed to static liquid Li for different time. The weight loss per square meter $(\Delta \mathrm{W})$ was calculated by the equation $\Delta \mathrm{W}=\left(\mathrm{m}_{1}-\mathrm{m}_{0}\right) / \mathrm{S}$, where $S$ is the surface area of each specimen, $\mathrm{m}_{1}$ and $\mathrm{m}_{0}$ are the weights of corroded and initial specimens, respectively. The weight loss for 304SS specimens at different time were shown in Fig. 2. The results indicate that the weight loss for 304SS specimens showed a power law trend (power of 1/2) with time. After being dipped into liquid Li for 1584 hours, the weight loss rate was about $5.7 \times 10^{-4} \mathrm{~g} / \mathrm{m}^{2} / \mathrm{h}$. The weight loss of 304SS specimens was about $0.895 \mathrm{~g} / \mathrm{m}^{2}$, equivalent to a thickness of $113 \mathrm{~nm}$ upon an assumption of $7.93 \mathrm{~g} / \mathrm{cm}^{3}$ as the density of $304 \mathrm{SS}$ specimens.

It's well known that the alloy elements, such as $\mathrm{C}, \mathrm{Cr}, \mathrm{Fe}, \mathrm{Ni}$ and $\mathrm{Mn}$, can be dissolved easily in liquid metal [30, 37-39]. The weight loss of 304SS specimens in the liquid $\mathrm{Li}$ can be attributed to the dissolution of $\mathrm{C}, \mathrm{Cr}, \mathrm{Mn}, \mathrm{Fe}$ and $\mathrm{Ni}$ in the alloy and the formation of corrosion products on specimen surface. Firstly, the specimen's mass was badly lost due to elements in the alloy dissolved in liquid Li with a constant dissolution rate. Then, the corrosion products were made of dissolved elements on the surface. Finally, the specimen's mass loss tended to constant because of the dissolution of elements in alloy was almost saturated in bulk $\mathrm{Li}$, or the corrosion products covered all surface to form a saturated layer of dissolved elements in liquid 
Li near the specimen's surface, as described below. Moreover, the concentration and mass of $\mathrm{C}$ and $\mathrm{Mn}$ in 304SS are much less than those of $\mathrm{Fe}, \mathrm{Cr}$ and $\mathrm{Ni}$, therefore the contribution from the $\mathrm{C}$ and $\mathrm{Mn}$ depletion on the mass loss is small.

\subsection{Microstructure change of specimens}

Fig. 3 shows the microstructures of 304SS specimens measured by SEM. Six surface morphologies after the corrosion tests from 0 to 1584 hours have been shown respectively. As shown in Fig. 3(a), the 304SS specimen without corrosion test exhibits many nicks on the surface because of mechanical processing. After exposure to liquid Li, the specimens' surface lost the metallic luster and showed a non-uniform brightness, indicating some inhomogeneous corrosion. Many corroded particles adhered to the specimens' surface and their numbers increased significantly after being tested for 1320 hours, which indicated that the extent of corrosion increases with corrosion time. At higher magnification, the appearance of the corroded particles are typically spinel-like, with the sizes of $1 \sim 2 \mu \mathrm{m}$, as shown in Fig. 4. One can expect the following two possibilities for the spinel-like structures: (1) large precipitates, and (2) corrosion products by Li. It was found the particles preferred to accumulate along the machining marks and grew up with time, as shown in Fig. 5, and finally they almost covered all surfaces. To uncover the compositions of particles in the corroded region, EDS surface analysis was performed to obtain the elements profiles. The results showed that the main component elements of particles were $\mathrm{Cr}$, $\mathrm{Fe}$ and $\mathrm{C}$, as Fig. 6(f) shown, its main composition was $\mathrm{M}_{23} \mathrm{C}_{6}(\mathrm{M}$ : $\mathrm{Cr}$, Fe). The XRD surface analysis was performed to obtain the elements profiles of specimen's surface, the Cr and Fe carbides were also observed on the surface, as shown in Fig.6 (e). Fig. 7 shows that the material of 304SS specimen being exposed to static Li at $600 \mathrm{~K}$ for 792 hours is single-phase of austenite. By metallographic examination, the 304SS specimens 
demonstrated non-uniform corrosion morphology by liquid $\mathrm{Li}$, and there existed a lot of grain boundaries which were just like bold black lines. It was found that the essence of bold black line was chromium-depleted zone, which means the corrosion specimens suffered from a typical corrosive attack due to the dissolution of $\mathrm{Cr}$ element near the grain boundaries in liquid Li. Both the metallographic examination and EDS analyses indicate that the intensive spinel-like particles on the surface of the specimens being exposed to liquid $\mathrm{Li}$ were large precipitates of $\mathrm{M}_{23} \mathrm{C}_{6}$, which probably resulted from the liquid Li penetration along grain boundaries. The solubility of $\mathrm{C}$ in liquid $\mathrm{Li}$ is much higher than $\mathrm{Fe}$ and $\mathrm{Cr}$, as reported by Natesan et al. [39] and the $\mathrm{C}$ is assumed to be dissolved as $\mathrm{Li}_{2} \mathrm{C}_{2}$ at low concentration of $\mathrm{N}_{2}$ [40]. The chemical reactions of $6 \mathrm{Fe}+\mathrm{Li}_{2} \mathrm{C}_{2} \rightarrow 2 \mathrm{Fe}_{3} \mathrm{C}+2 \mathrm{Li}$ and $7.66 \mathrm{Cr}+\mathrm{Li}_{2} \mathrm{C}_{2} \rightarrow$ $0.3333 \mathrm{Cr}_{23} \mathrm{C}_{6}+2 \mathrm{Li}$ can occur on the surface of specimens, and these are the reactions for $\mathrm{C}$ depletion from the alloy to the surface facing the liquid Li. But the Gibbs-free energy of $\mathrm{Cr}_{23} \mathrm{C}_{6}(-65 \mathrm{KJ} / \mathrm{mol})$ was lower than $\mathrm{Fe}_{3} \mathrm{C}(10 \mathrm{KJ} / \mathrm{mol})$ and $\mathrm{Mo}_{\chi} \mathrm{C}$ at $600 \mathrm{~K}$ in liquid $\mathrm{Li}$ [26]. It illustrates that the Fe does not react with $\mathrm{Li}_{2} \mathrm{C}_{2}$ easily, because the reaction is not spontaneous. According to Fig. 6(e), it was also confirmed that the dissolved elements $\mathrm{Fe}$ and $\mathrm{Cr}$ could react with $\mathrm{Li}_{2} \mathrm{C}_{2}$ to form $\mathrm{Fe}$ and $\mathrm{Cr}$ carbides and even form complex products of $\mathrm{Cr}_{x} \mathrm{Fe}_{\mathrm{y}} \mathrm{C}_{\mathrm{z}}$ on the surface of 304SS specimen under this operation condition. As reported by $Q i X u$ et al. [27], the carbon potential in Li was controlled by forming $\mathrm{Mo}$ and $\mathrm{Nb}$ carbides on inner surface of the Mo and $\mathrm{Nb}$ crucible. From these results it can deduced that the carbon potential in Li could also be controlled by forming $\mathrm{Cr}$ carbide. Furthermore, the diffusion energy for $\mathrm{Cr}$ along grain boundary and in grains were $162 \sim 252 \mathrm{KJ} / \mathrm{mol}$ and $540 \mathrm{KJ} / \mathrm{mol}$, respectively. Therefore, the formation of $\mathrm{Cr}_{23} \mathrm{C}_{6}$ on grain boundaries was easily.

Moreover, as shown in Fig. 6, a lot of holes were found on the specimens' surfaces 
after being exposed to liquid $\mathrm{Li}$, and their sizes became larger as increasing the test time. However, the area ratios of holes decreased with test time. After being dipped into liquid Li for 1584 hours, the area ratio of holes was about 55\%. Fig. 6 (d) indicates that after exposed, parts of a porous but still adherent layer were observed on the attacked steel surface, and parts of surface were hardly damaged. Similar results have been obtained that the dissolution of carbides into liquid Li resulted in some holes near the surface during investigating the compatibility of static liquid $\mathrm{Li}$ and JLF-1 steel [26]. The phenomenon was also found in some corrosion tests on ferritic-martensitic steel in $\mathrm{Pb}-17 \mathrm{Li}$ under dynamic conditions at $480{ }^{\circ} \mathrm{C}$ up to 8000 hours [41]. The result of line scan across the cross-section measured on 304SS specimen after exposure time for 1584 hours was presented in Fig. 8. The figure revealed a depletion of $\mathrm{Cr}$ and $\mathrm{Fe}$ near the surface. The thickness of corrosion layer was about $2 \mu \mathrm{m}$ which was deeper than the calculated value. This was mainly due to that the carbides precipitates were not removed from the specimens surface when measured the weight loss of specimens.

As confirmed by other experiments [33-35, 42], the formation of $\mathrm{M}_{23} \mathrm{C}_{6}$ carbides at grain boundaries favored the penetration of $\mathrm{Li}$. The formation of $\mathrm{M}_{23} \mathrm{C}_{6}$ precipitates could enhance the dissolution of C, Fe, and Cr in the vicinity of the 304SS specimens' grain boundaries, which led to the matrix being dissolved much easier in these areas. The formation and mass transferring of Li compound also induce $\mathrm{Li}$ penetrating into the grain boundaries. Although the $\mathrm{N}$ concentration was not found in the specimens in the present study, the combination of a turbo-molecular pump was kept be operating to obtain a high vacuum. But there was about $0.0027 \mathrm{wt} \% \mathrm{~N}$ found in liquid Li. The solubility of $\mathrm{N}$ was higher than that of $\mathrm{Cr}$ and $\mathrm{Fe}$ in liquid $\mathrm{Li}$ at high temperature [32-33], and the dissolved $\mathrm{N}$ can react easily with $\mathrm{Li}$ and $\mathrm{Cr}$ or $\mathrm{Fe}$ to form some 
corrosion products, such as $\mathrm{Li}_{9} \mathrm{CrN}_{5}$ and $\mathrm{Li}_{3} \mathrm{FeN}_{2}$, at high-angle grain boundaries [42]. $\mathrm{Li}_{9} \mathrm{CrN}_{5}$ and $\mathrm{Li}_{3} \mathrm{FeN}_{2}$ have a tunnel-like structure, which can promote fast exchange of the elements and lead to the penetration of $\mathrm{Li}$ into grain boundaries in steels [30]. The corrosion products and covered Li were dissolved when the surface of 304SS specimen was cleaned with water. The porous but still adherent layer was appeared on surface and there was almost no corrosion products adhered on the surface.

\subsection{Hardness change of specimens}

To investigate the influence of Li corrosion on mechanical properties, Vickers hardness tests were carried out on the surface of specimens before and after the $\mathrm{Li}$ exposure. Fig. 9 shows the variation of hardness as a function of time after the specimens being dipped into static Li at $600 \mathrm{~K}$ under high vacuum conditions. The hardness of 304SS specimens without corrosion was about $185 \mathrm{HV}$. After exposure to liquid Li for 1584 hours, the hardness of 304SS specimens increased to $231 \mathrm{HV}$. It's also found that the hardness of 304SS specimens increased with the corrosion time. The area ratio of particles at the same time was also plotted in the figure. It's interesting that the hardness of 304SS specimens increases with the area ratio of precipitates.

In order to investigate the relationship between hardness of steel surface and area ratio of grains, the hardness on different surface positions was measured and compared, as shown in Fig. 10. The figure revealed that the hardness was higher at the positions covered by $\mathrm{M}_{23} \mathrm{C}_{6}$ grains. Combining with Figs. 9 and 10, it was quite clear that the grains play an important role in hardness, and the hardness of 304SS specimens increases with the increase of concentration and mass of grains on the surfaces. It's known that $\mathrm{Cr}$ is a C-trapper [43] and it can get $\mathrm{C}$ atoms from liquid $\mathrm{Li}$ 
and reduce the $\mathrm{C}$ concentration in liquid $\mathrm{Li}$; then the equilibrium of $\mathrm{C}$ in liquid $\mathrm{Li}$ will be broken, which further lead to the depletion of $\mathrm{C}$ in the specimens and the increase of the hardness. Barker and Frankham [44] investigated the effects of $\mathrm{C}$ and $\mathrm{N}$ on the corrosion resistance of typical $316 \mathrm{SS}$ specimens in liquid $\mathrm{Li}$, and they also found the hardness of those 316SS specimens increased with the concentration of carbon. Moreover, the increase of hardness of 304SS specimens can be divided into two stages. The hardness increased fast before the corrosion time of 528 hours and the average hardness increase rate was about 0.429 . From 528 to 1584 hours, the hardness increased slowly, and the increase rate of average hardness was about 0.005 . In the first stage, $\mathrm{C}, \mathrm{Cr}, \mathrm{Fe}$ and Mo can be dissolved easily into liquid $\mathrm{Li}$; and then the carbides of $\mathrm{M}_{23} \mathrm{C}_{6}$ type formed. In the second stage, the dissolution of $\mathrm{Fe}, \mathrm{Cr}, \mathrm{Mn}$ and C was almost saturated in bulk $\mathrm{Li}$, or the saturated layer of dissolved elements formatted in liquid $\mathrm{Li}$ near the specimen's surface; the formation of $\mathrm{M}_{23} \mathrm{C}_{6}$ was difficult and less.

\section{Conclusion}

The compatibility of $304 \mathrm{SS}$ specimens with static liquid $\mathrm{Li}$ at $600 \mathrm{k}$ under high vacuum condition was investigated. It was found that

(1) After 1584 hours exposure to liquid $\mathrm{Li}$, the 304SS specimens exhibited a power law trend of weight loss with the exposure duration time, the weight loss was $\sim 0.895 \mathrm{~g} / \mathrm{m}^{2}$, equivalent to $\sim 113 \mathrm{~nm}$ thickness of $304 \mathrm{SS}$ specimens.

(2) Due to the dissolution of $\mathrm{C}, \mathrm{Cr}, \mathrm{Fe}$ and $\mathrm{Mn}$ into liquid $\mathrm{Li}$, the porous corroded morphologies appeared on the surface of 304SS specimens.

(3) 304SS demonstrated a non-uniform corrosion behavior by preferential grain boundary attack, due to the formation of $\mathrm{M}_{23} \mathrm{C}_{6}$ carbides and/or Li compound at 
grain boundaries in favor of the Li penetration.

(4) Due to the formation of $\mathrm{M}_{23} \mathrm{C}_{6}$ carbides on surface, the surface hardness of 304SS specimens had a slight increase after exposure to liquid Li.

\section{Acknowledgement}

This research is funded by the National Magnetic confinement Fusion Science Program under the contract Nos. 2013GB114004, 2013GB114001 and the National Nature Science Foundation of China under the contract Nos. 11405210, 11321092 and

51371080. This work was also partly supported by the Japan Society for the

Promotion of Science-National Research Foundation of Korea-National Science Foundation of China (JSPS-NRF-NSFC) A3 Foresight Program in the field of Plasma Physics (NSFC No. 11261140328).

\section{References}

[1] D.K. Mansfield, et al., Phys. Plasmas 3 (1996) 1892.

[2] Z.Sun, et al., Fus. Eng. Des. 89 (2014) 2886.

[3] J. Sánchez, et al., Nucl. Fusion 49 (2009) 104018.

[4] R. Maingi, et al., Nucl. Fusion 50 (2010) 064010.

[5] D.K. Mansfield, et al., Nucl. Fusion 41 (2001) 1823.

[6] J.S. Hu, et al., Phy. Rev. Lett. 114 (2015) 055001.

[7] J. Ren, et al., Phys. Scr. T159 (2014) 014033.

[8] T.D. Rognlien., J. Nucl. Mater. 290-293 (2001) 312.

[9] V. Pericoli-Ridolfini, Plasma Phys. Control. Fusion 49 (2007) S123.

[10] V. Pericoli-Ridolfini, et al., Nucl. Fusion 47 (2007) S608-S621. 
[11] S.V. Mirnov, et al., Plasma Phys. Controlled Fusion 48 (2006) 821.

[12] K. Ushigusa, et al., Fusion Eng. Des. 45 (1999) 137-144.

[13] R. Kaita, et al., J. Nucl. Mater. 337 (2005) 872.

[14] R. Majeski, et al., Nucl. Fusion 45 (2005) 519.

[15] J.S. Hu, et al., Fusion Eng. Des. 85 (2010) 930.

[16] G.Z. Zuo, et al., J. Nucl. Mater. 415 (2011) S1062.

[17] Z. Sun, et al., J. Nucl. Mater. 438 (2013) S899.

[18] G.Z. Zuo, et al., Fusion Eng. Des. 89 (2014) 2845.

[19] X.C. Meng, et al.,Acta Phys. Sin. 64 (2015) 212801.

[20] J.S. Hu, et al., Fusion Eng. Des. 89 (2014) 2875.

[21] J. Ren, et al., Rev. Sci. Instrum. 82(2015) 23504.

[22] J.S. Hu, et al., Nucl. Fusion. 56 (2016) 046011.

[23] H. Kondo, et al., J. Eng GasTurb.Power 133 (2011).

[24] H. Kondo, et al., Nucl. Fusion. 51 (2011) 123008.

[25] Qi. Xu, et al., Fusion. Sc. Technol. 52 (2007) 609.

[26] Qi. Xu, et al., Fusion Eng. Des. 83 (2008) 1477.

[27] Qi. Xu, et al., J. Nucl.Mater. 394 (2009) 20.

[28]Masatoshi Kondo, et al., J. Nucl. Mater. 417 (2011) 1200

[29] Masatoshi Kondo, et al., Fusion Eng. Des. 87 (2012) 1777

[30] Y.F. Li, et al., J. Nucl. Mater. 443 (2013) 200.

[31] P.F. Tortorelli, J. Nucl. Mater. 155-157 (1988) 722

[32] R.J. Pulham, et al., J. Nucl. Mater. 115 (1983) 239

[33] M. Kondo, et al., Fusion Eng. Des. 87(2012) 1777.

[34] V. Tsisar, et al., J. Nucl. Mater. 417 (2011) 1205.

[35] A. Kimura, et al., Fus. Eng. Des. 81 (2006) 909. 
[36] G.Z. Zuo, et al., Rev. Sci. Instrum. 85, (2014) 023506.

[37] O.K. Chopra, et al., J. Nucl. Mater. 103-104 (1981) 651.

[38]I.E. Lyublinski, et al., J. Nucl.Mater. 224 (1995) 288.

[39] K. Natesan, et al., J. Nucl. Mater. 115 (1983) 251.

[40] R.J. Pulham, et al., J. Nucl. Mater. 115 (1983) 239.

[41] H. Glasbrenner, et al., J. Nucl. Mater. 283-287 (2000) 1332.

[42] E. Ruedl, et al.,J. Nucl. Mater. 116 (1983) 112.

[43] M.A. Abdou, et al.,Fus. Eng. Des. 54 (2001) 181.

[44] M.G.Barker, et al.,J. Nucl. Mater. 107 (1982) 218. 


\section{Table list}

Table. 1 The initial impurities content of metal Li.

\begin{tabular}{ccccccccccc}
\hline Element & Na & K & Ca & Fe & N & Si & Cl & Al & Ni & Cu \\
\hline $\begin{array}{c}\text { Max Content } \\
\text { ration \% }\end{array}$ & 0.0045 & 0.0002 & 0.0015 & 0.003 & 0.0027 & 0.0020 & 0.002 & 0.001 & 0.002 & 0.001 \\
\hline
\end{tabular}




\section{Figures list}

Fig. 1 The schematic diagram of static liquid Li testing device: 1 . main react vessel; 2 . sampling system; 3. Specimens; 4. turbo-molecular pump; 5. vacuum gauge; 6. leak detector; 7. pressure controller; 8. VED electromagnetic valve; 9. electromagnetic valve; 10. Argon; 11. Observation window

Fig. 2 The weight loss of 304SS versus exposure time in liquid Li at $600 \mathrm{~K}$

Fig. 3 The microstructures of 304SS before and after being dipped into liquid Li at $600 \mathrm{~K}$. (a) before test; (b) exposure to liquid Li for 264h; (c) exposure to liquid Li for 528h; (d) exposure to liquid Li for 792h; (e) exposure to liquid Li for 1320h; (f) exposure to liquid $\mathrm{Li}$ for $1584 \mathrm{~h}$.

Fig. 4 The spinel-like appearance of particles

Fig. 5 The evolution of particles versus exposure time: (a) exposure to liquid Li for 264h; (b) exposure to liquid Li for 528h; (c) exposure to liquid Li for $792 \mathrm{~h}$.

Fig.6 The appearance of steel surface: (a) exposure to liquid Li for 264h; (b) exposure to liquid Li for 528h; (c) exposure to liquid Li for 792h; (d) exposure to liquid Li for 1320h; (e) XRD surface analysis for 304SS specimen's surface after exposure to liquid Li for 1320h; (f) elements profiles by EDS scanning of 304SS exposed to Li for $1320 \mathrm{~h}$ at $600 \mathrm{~K}$.

Fig.7 The metallographic structure of corrode sample after exposure to static $\mathrm{Li}$ at 600 K for $792 h$.

Fig.8 Elements profiles by EDS line scanning of 304SS exposed to Li for 1584h at $600 \mathrm{~K}$. 
Fig. 9 Vickers hardness curve on 304SS surface before and after exposure to static Li at $600 \mathrm{~K}$ for $0 \mathrm{~h}$ to $1584 \mathrm{~h}$, compared with area ratio of precipitates at the same time.

Fig.10 The different Vickers hardness values with different surface positions. 
Fig.1

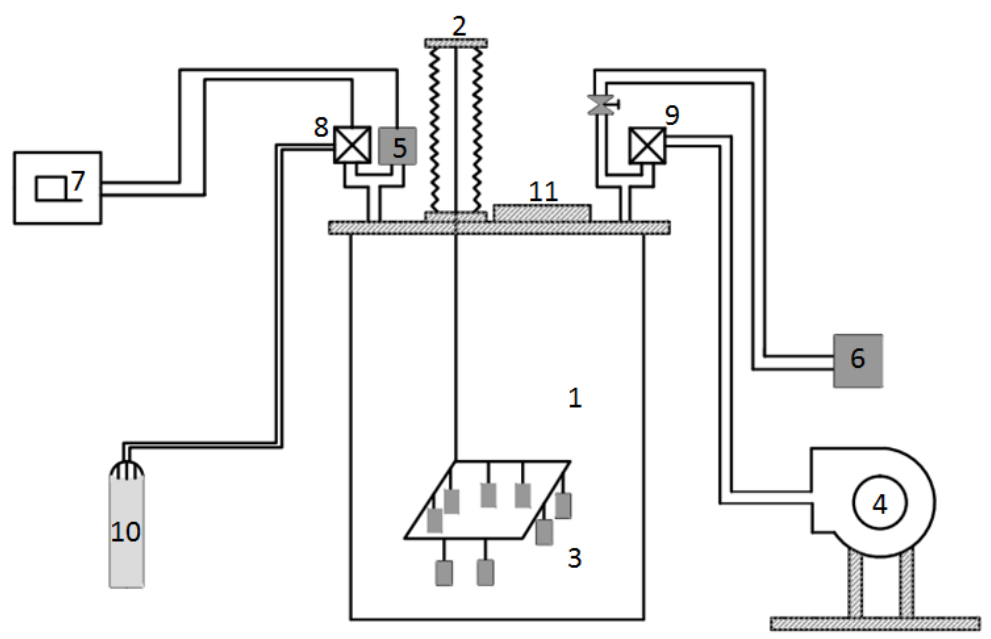


Fig.2

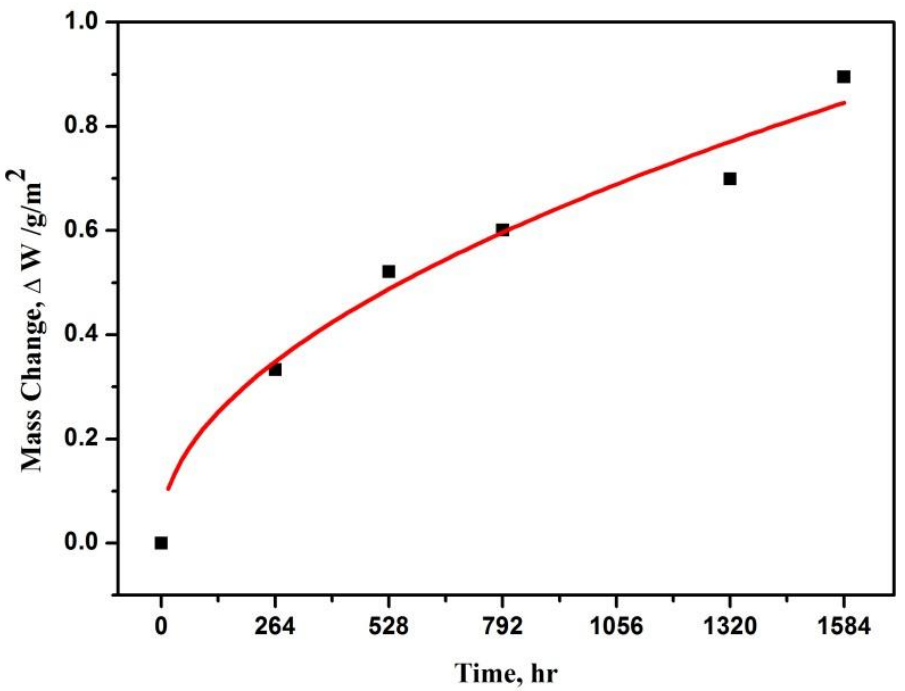


Fig.3

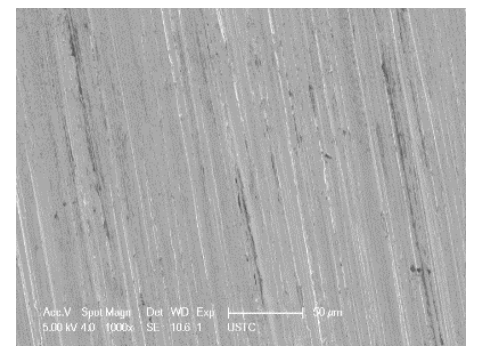

(a)

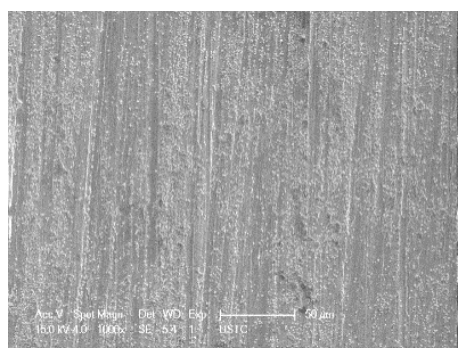

(d)

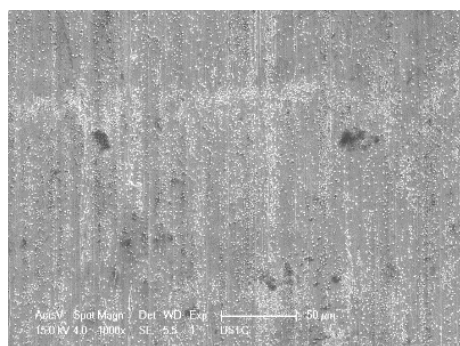

(b)

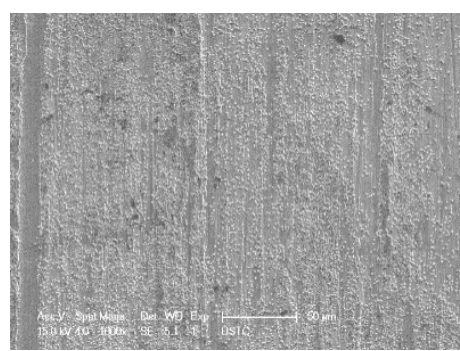

(e)

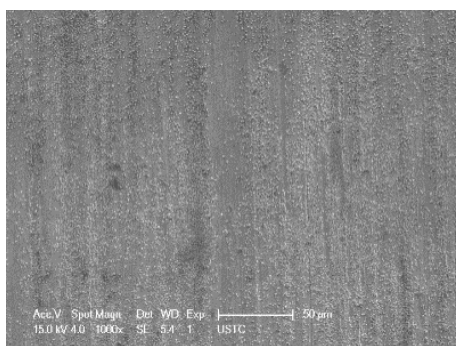

(c)

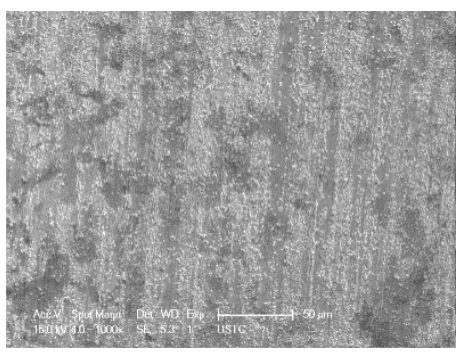

(f) 
Fig.4

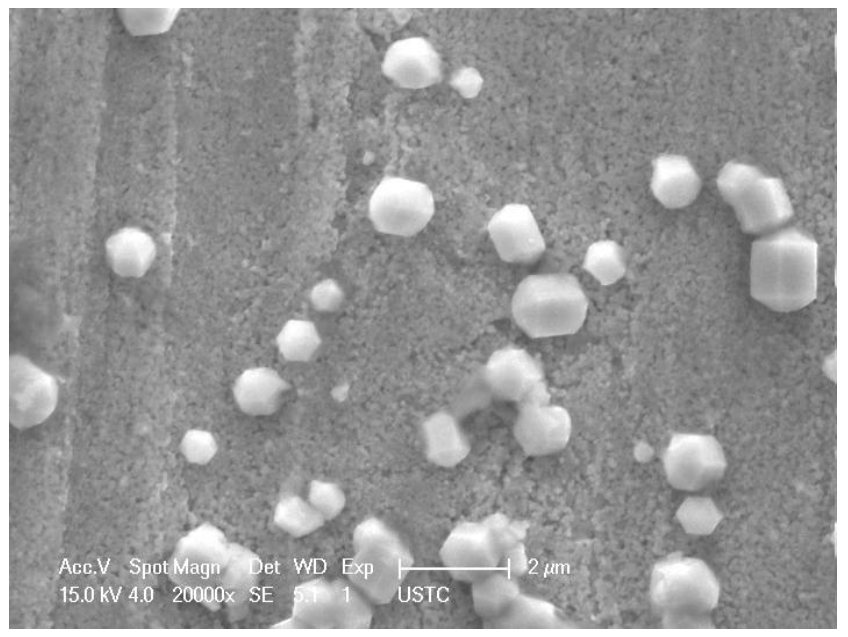




\section{Fig.5}

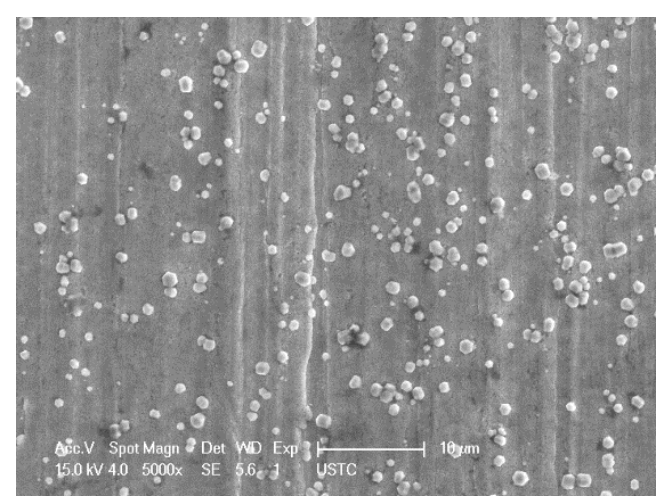

(a)

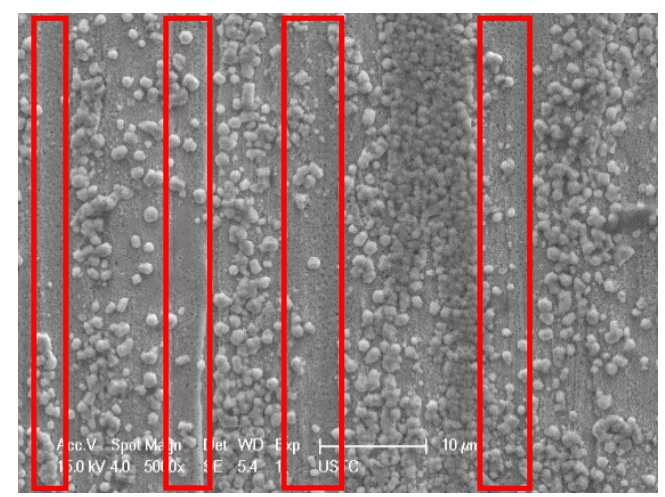

(c)

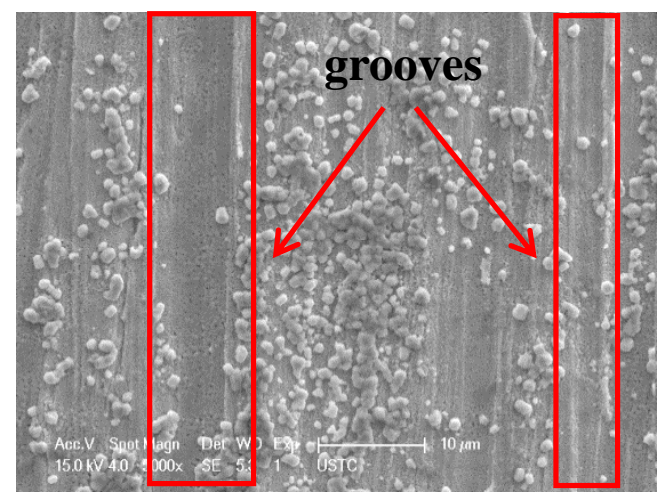

(b)

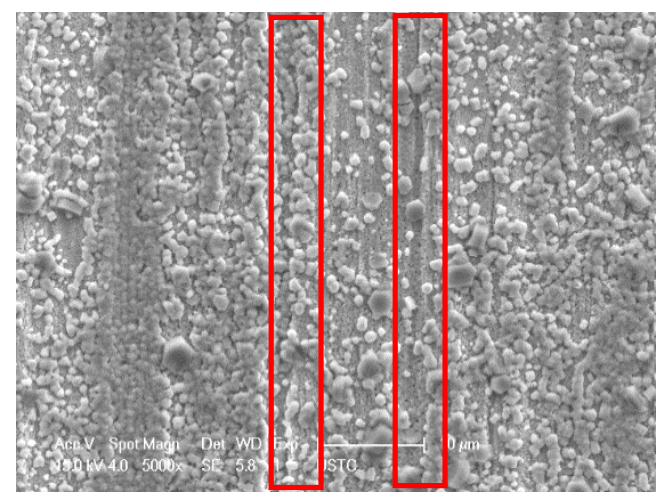

(d) 
Fig.6

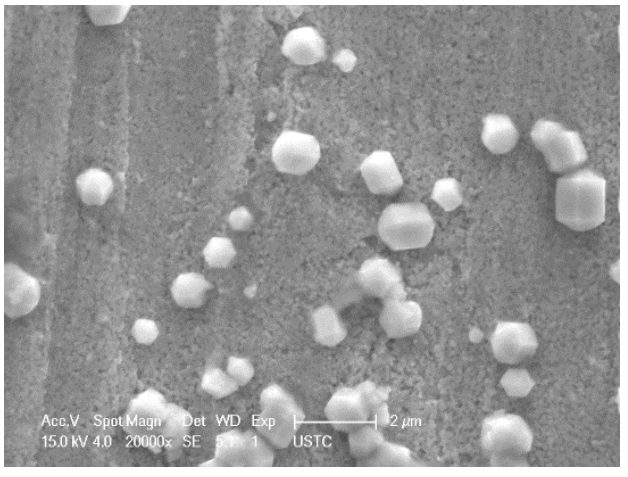

(a)

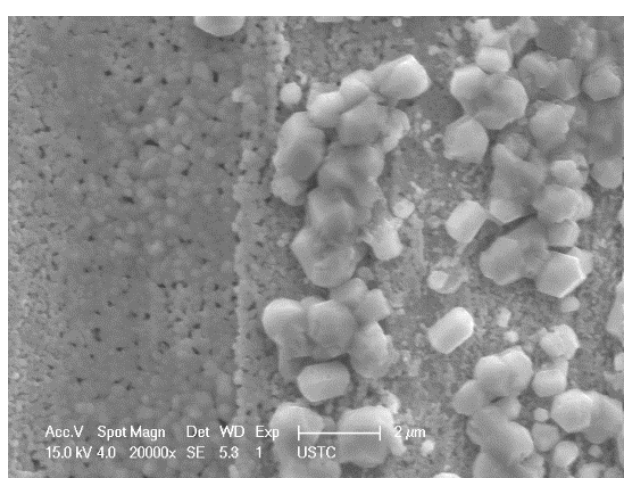

(b)

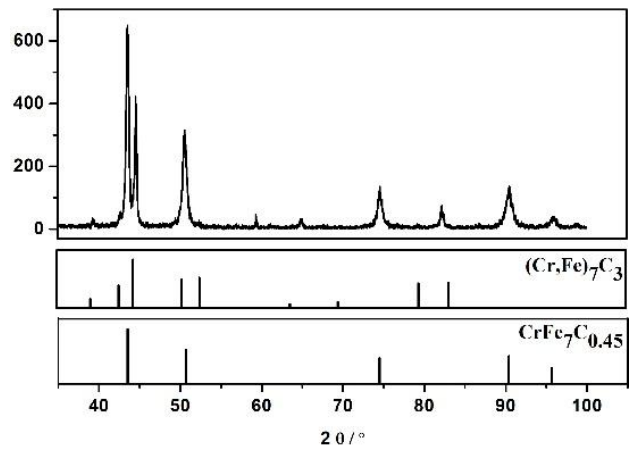

(e)

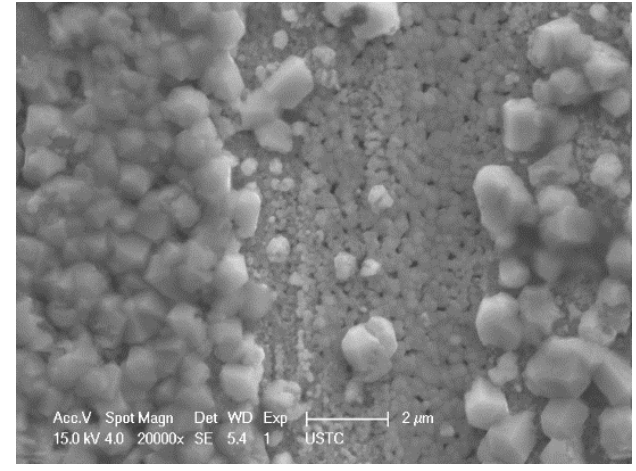

(b)
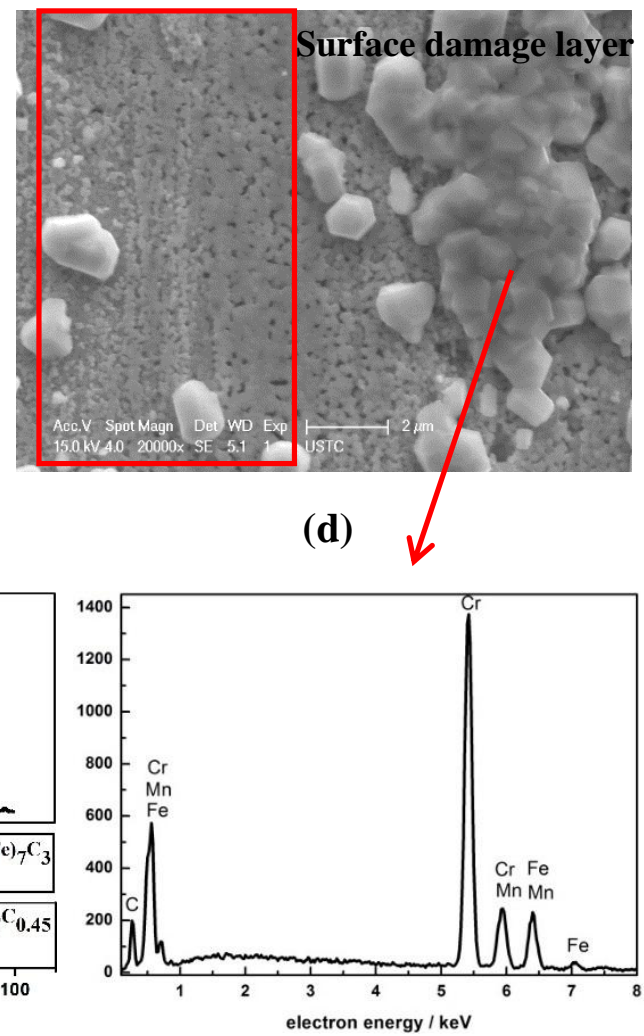

(f) 
Fig.7

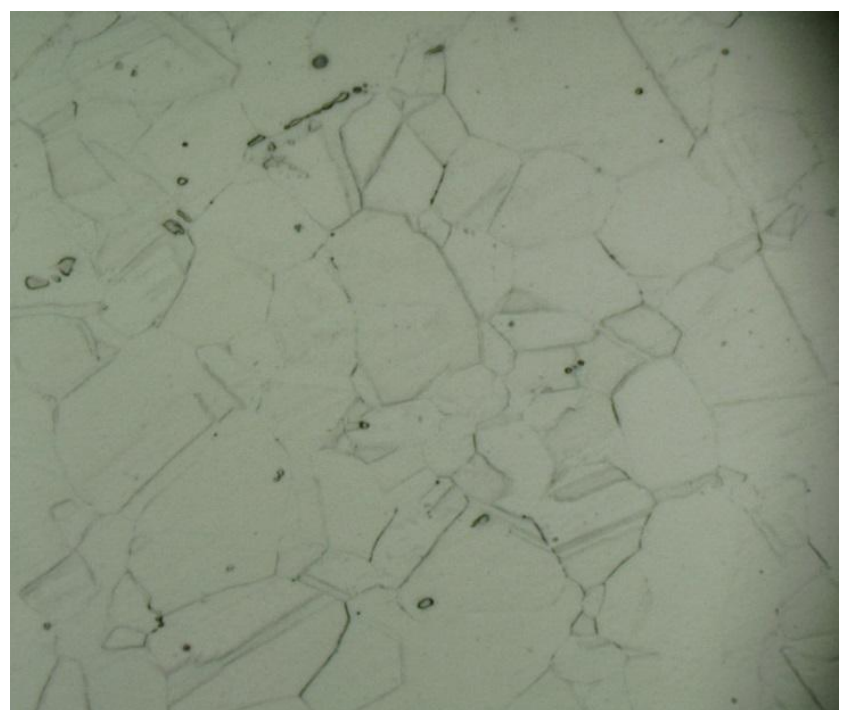


Fig.8

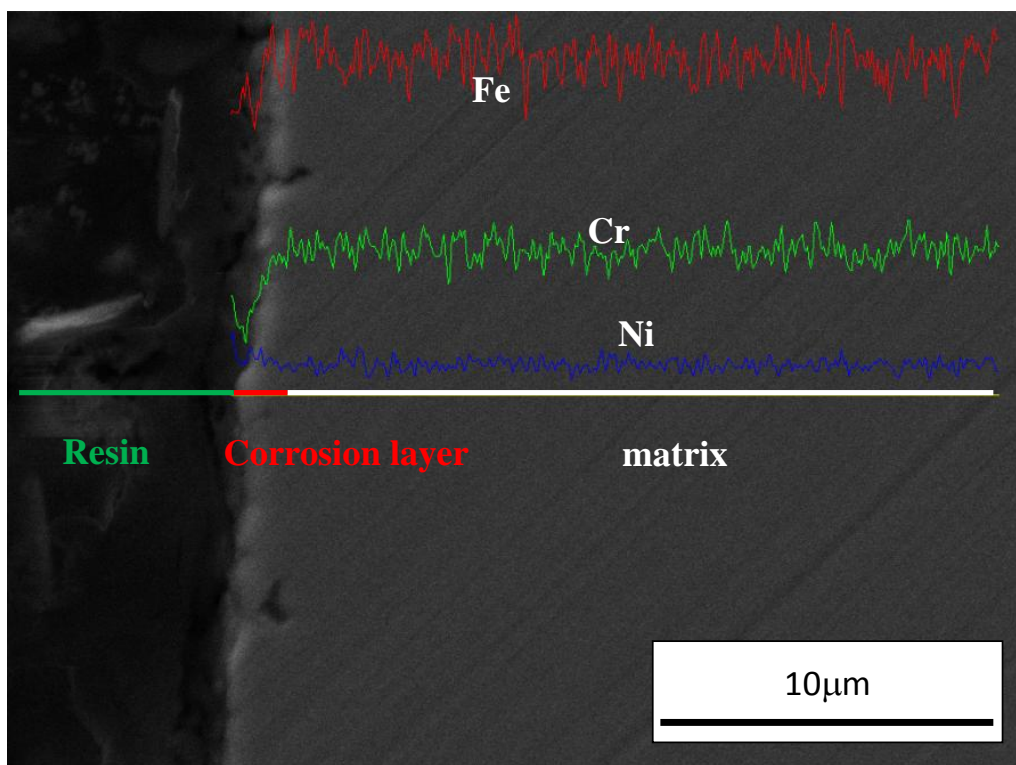


Fig.9

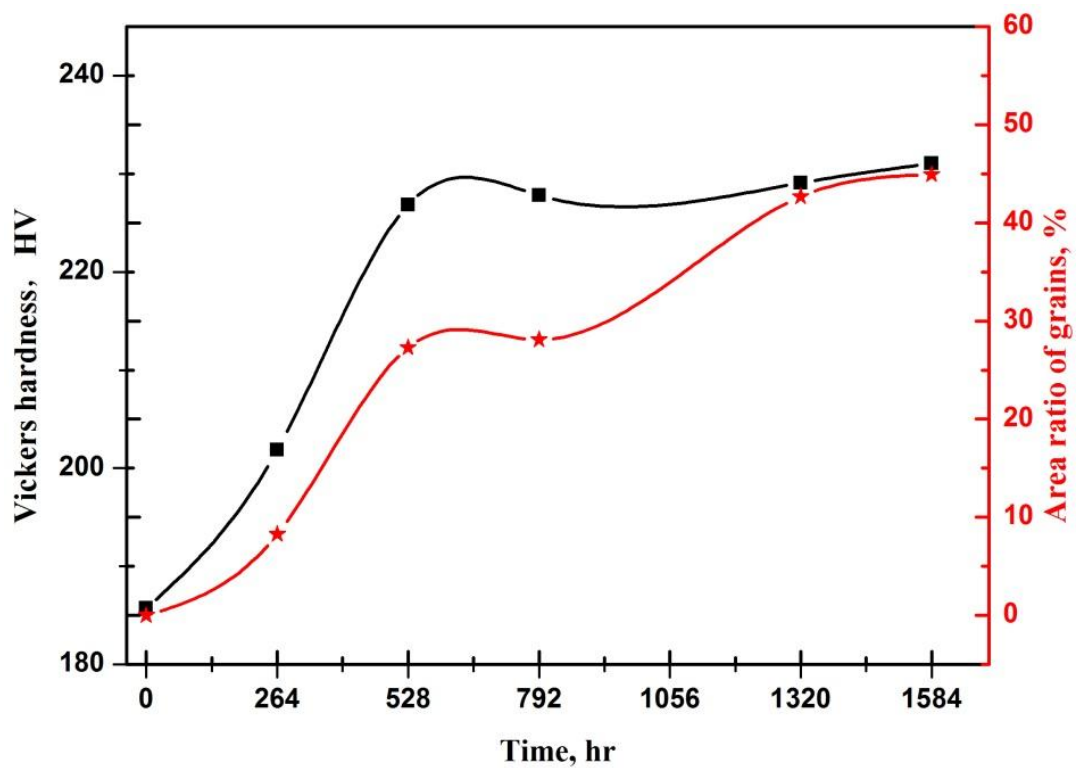


Fig.10

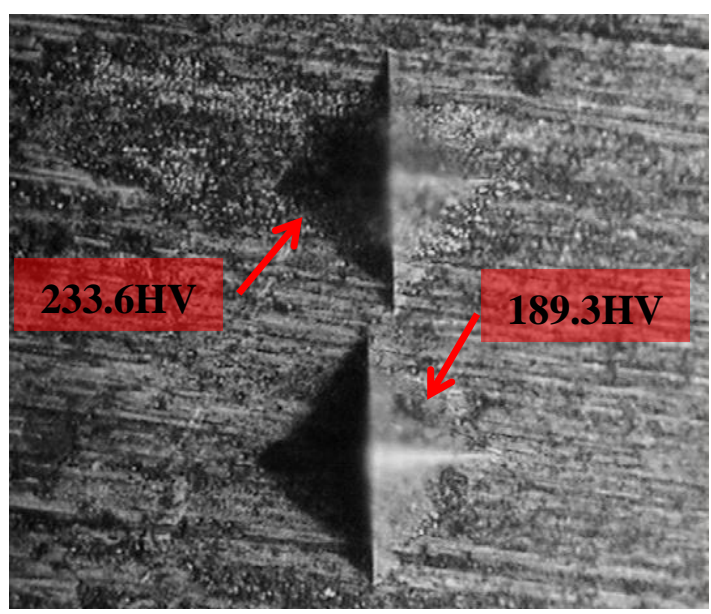

